\title{
O Jazz de Bill Evans: formação, influências, obras e estilo composicional
}

\author{
J. William Murray (Towson University, Towson, EUA) \\ jwilliammurray@comcast.net \\ Tradução de Fausto Borém (UFMG, Belo Horizonte, MG) \\ fborem@ufmg.br
}

Resumo: Estudo estilístico sobre a música do compositor e pianista norte-americano Bill Evans. Inclui um contexto sobre os pianistas, compositores (eruditos e populares) e o teórico do jazz George Russell, que marcaram sua formação musical. A análise de 19 obras selecionadas de Bill Evans revela características estilísticas relacionadas ao estilo/andamento, métrica, tonalidade, forma, duração, ritmo harmônico, linguagem harmônica e outros detalhes relevantes.

Palavras chave: ecletismo de Bill Evans; hibridismo em música; música francesa e jazz modal jazz; transformação e improvisação musical; influência entre música erudita e popular.

\section{Bill Evans's jazz: background, influences, works and compositional style}

Abstract: Style study on the music of American composer and pianist Billy Evans. It includes a historical context on pianists, composers (both popular and classical) and the jazz theorist George Russell who influenced his music. The analysis of 19 selected works of Bill Evans. reveals traits related to style/tempo, time signature, tonality, form, length, harmonic chord pace and harmonic language and some other relevant details.

Keywords: eclecticism of Bill Evans; hybridism in music; French music and modal jazz; music transformation and improvisation; influence between classical and popular music.

\section{1 - Introdução}

Compositores de diversos estilos musicais são influenciados pelo sons que ouvem. Entre esses que de fato ressoam dentro deles, alguns elementos musicais aparecerão em sua música. Além desta influência por meio do processo de escuta, elementos musicais de outros compositores são absorvidos ao se estudar uma obra, analisá-la ou transcrevê-la. Mais do que isso, a consciência sobre os procedimentos composicionais e fundamentos teóricos aí envolvidos pode se refletir na música que o compositor influenciado escreve ou arranja.

Devido à junção de todos esses fatores, e de outros que não são pertinentes no escopo desse estudo, não é muito fácil determinar com precisão a presença de um compositor na música de outro. Entretanto, quase sempre os compositores são capazes de nomear alguns nomes mais importantes dentre os que os influenciaram. No meu caso, há dois compositores: Bill Evans (19291980) e Billy Strayhorn (1915-1967), cujas composições particularmente ressoam em mim (veja estudo estilístico sobre a música de Bill Strayhorn no número 29 de PerMusi). Mas porque sou atraído por esses compositores? Porque aprecio ouvi-los? Porque gosto de tocá-los ao piano? Essas têm sido questões que procuro responder (MURRAY, 2011).

Nesse estudo, proponho levantar as características composicionais de Bill Evans. Para isso, considero apenas as composições de que apareceram legalmente publicadas, especialmente no Bill Evans Fake Book de Pascal WETZEL (2003), que traz 55 obras. Parte integral do repertório do jazz, essas são músicas que os amantes e estudiosos do gênero, como eu, ouviram ao longo dos anos. Fake books são também as fontes primárias para se tocar essas composições ao piano que ressoam em milhões de pessoas.

Evans não foi prolífico e deixou cerca de 60 obras. Uma das lendas da história do jazz, ele se tornou mais conhecido por suas performances ao piano do que por 
suas composições. Seu estilo pianístico influenciou muitos pianistas e certamente teve um impacto no modelo de som que valorizo e admiro. Entretanto, muito embora Evans tenha influenciado minha maneira de tocar, não incluirei suas práticas de performance na minha análise no presente artigo, me restringindo apenas aos seus aspectos composicionais, verificados em 19 obras selecionadas (veja Exs. 1 e 2 abaixo).

\section{2 - A formação de Bill Evans}

Considerado um dos pianistas de jazz mais importantes de todos os tempos, Bill Evans mudou a maneira de tocar piano no jazz, influenciando pianistas como Herbie Hancok, Chick Corea, Keith Jarret, Hapton Hawes, Steve Khun, Alan Broadbent, Denny Zeitlin, Paul Bley, Michel Petrucciani e muitos outros. Gene Lees (FEATHER e GILTER, 1999, p.214) o considerou a maior influência pianística de sua geração, especialmente pela sua nova abordagem da sonoridade e da harmonia. Para James Lincoln COLLIER (1978, p.393), Evans representa a maior influência entre os pianistas desde a década de 1960: "[Evans mudou] a linguagem do piano no jazz moderno, incorporando procedimentos harmônios derivados dos impressionistas franceses, forjando um estilo coletivo conhecido pelo contraponto ao mesmo tempo rítmico e fluido" (TEACHOUT, 1998, p.46).

Quando o pianismo de Evans aparece em uma discussão sobre jazz, duas questões que geralmente vem à tona são seu estilo lírico e sua abordagem harmônica. Sua sonoridade única tornou-se diferente do que predominava em um período no qual o bebop reinava. Mesmo hoje, Evans é citado como um modelo pelos críticos de gravações de piano do jazz atual. É muito comum o comentário no qual o pianista que está sendo avaliado mostre influências de Bill Evans. Alguns dos trios de Bill Evans estão entre os melhores trios de jazz de todos os tempos. Ele e seus colegas de trio mudaram a natureza desta formação para algo de fato coletivo, ao contrário de uma formação em que se ouviam papéis bem delimitados para o piano, o contrabaixo e a bateria. 0 que hoje se tornou algo mais comum foi algo inteiramente novo na época em que Evans começou a fazê-lo.

Além de grande pianista, Evans também foi um grande compositor, embora muitos desconheçam esse fato, o que contribui para que não seja devidamente estudado ainda. Os livros, teses, dissertações e artigos sobre Evans tem tratado mais de seu estilo de performance e improvisação, mas não de seu estilo composicional.

O objetivo de uma composição de jazz é preparar o palco para a improvisação que se segue ao tema e, por isso, é sinônimo de improvisação e não de realização de notas escritas. Evans escreveu canções como precursoras de improvisações, mas ao mesmo tempo, acreditava firmemente que a improvisação era altamente dependente do que o tema original tinha a dizer (EVANS e EVANS, 2004). 0 performer, compositor e educador de jazz Harold Danko diz que

\begin{abstract}
"Em nenhum lugar podemos aprender mais sobre a linguagem musical de Bill Evans do que nas suas próprias composições. . - podemos aprender como ele chegou ao conteúdo musical por meio do processo de composição. . . ao longo dos anos, ele utilizou suas próprias composições como veículos para improvisação; e a presente geração pode seguir seus passos investigando sua importante produção como compositor" (WETZEL, 2003).
\end{abstract}

\section{3 - Influências sobre Bill Evans}

0 estilo composicional é influenciado diretamente pela formação da pessoa e a música com que tem contato, 0 que foi o caso de Bill Evans. Nascido em Plainfield, New Jersey em 1929, Bill Evans começou a estudar o piano aos seis anos. Mais tarde, estudou também o violino e a flauta, mas sempre foi mais interessado no piano (BIOGRAPHY RESOURCE CENTER, 2008). Por volta dos cinco anos, Evans costumava ouvir as aulas de piano de seu irmão Harry e podia repetir a música que ouvia. Com isso, conseguiu ter suas próprias aulas e passou a praticar o piano por até três horas por dia, como observa Peter PETTINGER, seu biógrafo em How a heart sings (1998, p.11).

Por volta dos sete anos, Evans começou a tocar o violino. Embora não fosse seu instrumento favorito, esta experiência pode tê-lo ajudado a desenvolver o estilo cantabile no piano pelo qual se tornou conhecido (PETTINGER, 1998, p.11). Nas notas da capa de seu disco Bill Evans: the complete Riverside Recordings, ele diz: "Acima de tudo, quero que minha música cante. . . deve passar aquela sensação maravilhosa do cantar" (WILLIAMS, 1984).

Dos 6 aos 13 anos, Bill Evans estudou o repertório do piano erudito, mas sem consciência de como a música era construida. Ganhou medalhas de ouro em competições tocando Mozart e Schubert. Desenvolveu o gosto por Delius, Debussy, Satie, Ravel, Grieg, Rachmaninoff e Chopin (SHADWICK, 2002, p.50). Nessa época, continuou a desenvolver sua habilidade de leitura à primeira vista tocando rigorosamente as notas escritas na partitura. Por volta dos 12 anos, começou a tocar, com seu irmão, numa banda para ensaios de aulas de dança na escola. Ali começou a descobrir o idioma do jazz, substituindo acordes para mudar a harmonia. Sua habilidade de leitura à primeira vista Ihe abriu muitas portas na região de Plainfield. Nessa época também começou a se interessar pelas formas musicais e procedimentos composicionais. Sozinho, passou a reduzir harmonicamente as composições que lhe interessava (PETTINGER, 1998, p.12-13).

Ao terminar a high school, Evans recebeu uma bolsa para estudar música no Southeastern Lousiana College, localizado a $80 \mathrm{Km}$ de New Orleans, passo que foi crucial na formação do seu estilo. No início da década de 1940, o estilo bebop estava surgindo em Nova lorque, estilo 
ao qual Evans não se expôs, devido à sua idade. Ao se mudar para longe de casa para estudar música, Evans ficou reservado o suficiente para desenvolver um estilo único, sem se deixar influenciar em demasia pelo bebop, estilo que estava predominando nos grandes centros do pais (PETTINGER, 1998, p.13).

$\mathrm{Na}$ faculdade Southeastern Lousiana College, Evans se concentrou no repertório erudito de piano, como mostra o programa de seu recital senior (Ex.1). Nessa época conviveu com incluiu sonatas de Mozart e Beethoven, bem como obras de Schumann, Rachmaninoff, Debussy, Ravel, Gershwin, Villa-Lobos, Khachaturian, Milhaud (PETTINGER, 1998, p.16), J. S. Bach, Chopin, Stravinsky e Scriabin (BIOGRAPHY RESOURCE CENTER, 2008).

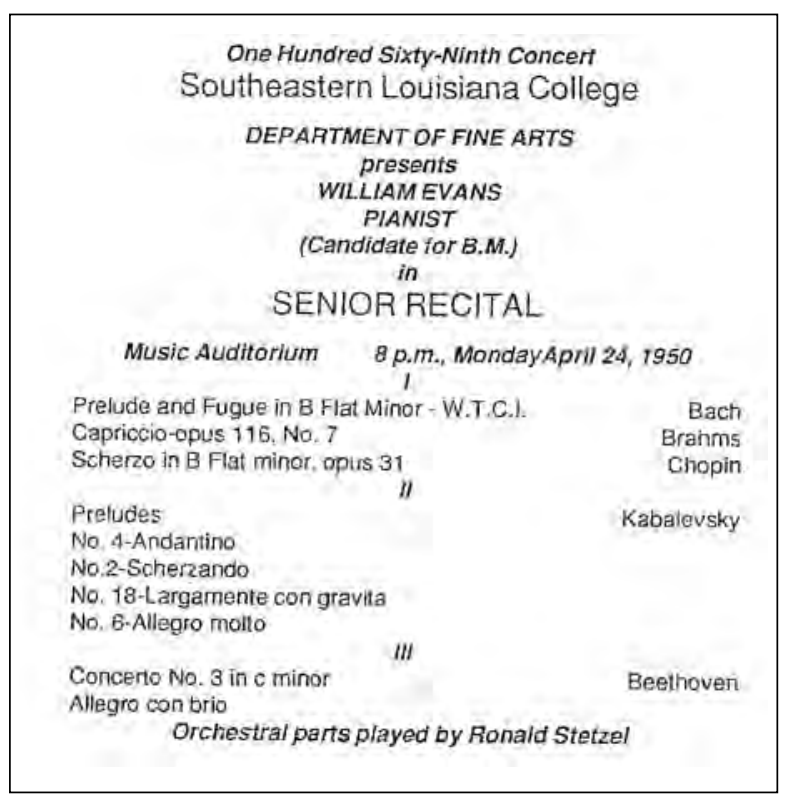

Ex.1 - Programa do recital senior de Bill Evans no Southeastern Lousiana College (NETHERCUTT, 1989, p.5).

Seu estudo de música erudita foi amplo e diverso, o qual Ihe permitiu desenvolver uma excelente técnica, o que ficou aparente em toda a sua carreira com jazzista. Mas sempre colocava essa bagagem a favor do conteúdo musical e nunca como mero virtuosismo. Tocar a música de Bach, ele afirmava, Ihe permitia ter mais contato com o teclado e controle sobre a sonoridade que o tornaria famoso (LYONS, 1983, p.226). Evans sempre foi adepto à ideia de trazer as técnicas da música ocidental europeia para o jazz. Elementos de Bach, Chopin, Debussy e Ravel são perceptíveis na sua escrita (La VERNE, 1990, p.8). No jazz, tornou-se hábil na reutilização de sutilezas harmônicas de um leque variado de compositores: das ambiguidades tonais de Debussy e Ravel até a sutileza de Satie, das estranhezas de Scriabin até os acordes espacializados de Bartók, passando pela bitonalidade de Milhaud (SHADWICK, 1960, p.64).

As características e técnicas que aprendeu na música erudita se tornaram aparentes nas suas composições e performances. Em 1966, Evans e seu irmão Harry prepararam um documentário sobre a natureza da música, jazz e improvisação (EVANS e EVANS, 2004). Para ele, o renascimento da música dos séculos XVIII e XIX seria o jazz, pois a improvisação havia sido um procedimento comum para mestres como Bach, Mozart e Chopin. Ele lamentava que a improvisação tivesse desaparecido à medida que mais importância foi dada à música escrita. Evans sentia que esses grandes compositores gostavam da liberdade da improvisação e a sensação de liberdade foi uma das razões pelas quais ele se inclinou para o lado do jazz, ao invés de se tornar um pianista de concertos eruditos. Entretanto, nunca abandonou suas raízes eruditas.

Na mesma época em que Evans estudava a música dos grandes compositores no Southeastern Lousiana College, também tocava regularmente em New Orleans e vizinhanças com seu trio chamado Casuals (SHADWICK, 2002, p.51). Tocava e escutava uma música bastante diferente da que aprendia na faculdade. Depois de servir ao exército por três anos e ficar um ano em casa estudando, decidiu, em 1955, entrar para a Mannes School of Music em Nova lorque para estudar composição, pois sentia que não havia aprendido ainda o suficiente. Nessa época, procurava também tocar jazz em todas as gigs possíveis. Assim, todo o tempo, Evans se expôs e realizava música de um variado leque de tradições musicais que está intimamente ligado ao desenvolvimento de seu estilo pessoal.

Não foram apenas os compositores eruditos que influenciaram sua performance e estilo composicional. Como ouvinte inveterado, absorveu na sua música muito daquilo que estava exposto no próprio mundo do jazz. Em uma entrevista para a revista francesa Jazz Times, ele disse:

"De Nat 'King' Cole pego o ritmo e a economia; de Dave Brubeck, um voicing particular; de George Shearing também um voicing, mas de outro tipo; de Oscar Peterson, o swing poderoso; de Earl Hines, o sentido estrutural. Bud Powell é completo, mas mesmo dele eu não pegaria tudo" (DOERSCHUK, 2001, p.146).

A maior influência pianística de jazz sobre Evans foi Nat "King" Cole, por cujo pianismo, abordagem melódica, clareza, frescor de ideias e sonoridade se apaixonou (PETTINGER, 1998, p.15). Outro pianista que teve grande impacto sobre Evans foi Lennie Tristano. Embora fossem diferentes sob muitos aspectos, Evans se identificou com a abordagem lógica e construção sonora de Tristano. Como ele, Evans precisava de uma base organizada para estruturar sua música, pois queria compreender teoricamente a estrutura de sua música (Mc PARTLAND, 1978). Entre outros pianistas de jazz que influenciaram Evans estão Horace Silver e Sonny Clark. Todos esses pianistas representam a ampla fonte na qual bebeu Evans. Mas ele aprendeu também com jazzistas nãopianistas com os quase tocava ou escutava, como Miles Davis, Dizzy Gillespie, Charlie Perker e Stan Getz (PETTINGER, 1998, p.15). Evans gostava de dizer que uma pessoa é "influenciada por centenas de pessoas e 
coisas, que aparecem no seu trabalho. Se prender a um apenas é ridículo" (SHADWICK, 1960, p. 52). De fato, aprendeu com todos.

Outra grande influência sobre Evans foi George Russell. Após se graduar no Southeastern Lousiana College e se mudar para Nova lorque, ele estudou e gravou com Russell, que havia desenvolvido um trabaho teórico chamado The Chromatic concept of tonal organization for improvisation (for all instruments). 0 conceito é baseado na convicção de Russell de que a escala Lídia com seu quarto grau aumentado, como meio de improvisação, é mais compatível com a tonalidade da escala maior do que a própria escala maior. 0 mundo melódico e harmônico de Russell foi rapidamente absorvido por Bill Evans (PETINGER, 1998, p.32). Esses conceitos começam a aparecer regularmente nas composições e improvisações de Evans. Um exemplo é Time remembered, na qual todos os acordes maiores contem uma \# 11 (décima primeira aumentada), indicando a presença da escala Lídia. Outro exemplo é Twelve tone tune two, na qual todos os acordes são maiores, com instruções para o improvisador utilizar o modo Lídio em todos os acordes. Evans disse que Russell compunha peças que soavam como improvisações e que, para compreendêlas, era necessário compreender todos os elementos de sua teoria musical (PETIINGER, 1998, p.32). Um dos objetivos de Evans era fazer com que sua música soasse espontânea (EVANS e EVANS, 2004). Assim, o trabalho teórico de Russell foi um dos pontos de partida para que Evans desenvolvesse sua ideias sobre fraseado, redução harmônica e o papel do voice leading harmônico que se tornou uma das marcas registradas de sua performance e estilo composicional (SHADWICK, 2002, p.15).

\section{4- A abordagem composicional de Bill Evans}

Embora tenha composto muitas peças e estudado composição, Bill Evans não se considerava um compositor profissional, mas um instrumentista que compunha. Em uma entrevista ao locutor de jazz canadense Ted O'Reilley em agosto de 1980, disse que em certo momento de sua carreira de músico precisou resolver o conflito entre seguir a o caminho da composição ou da performance. Embora gostasse de se dedicar seriamente à composição, se sentia mais um instrumentista do que um compositor, porque não escrevia todos os dias (O'REILLY, 1991, p.11).

A maior parte de suas composições pertence ao universo do jazz, especialmente para a formação do típico trio de jazz (piano, contrabaixo e bateria). Assim, utilizava suas composições como ponto de partida para improvisações. $\mathrm{Na}$ entrevista mencionada acima, Evans diz que as peças em estilos diversos que escreveu enquanto aluno em Mannes não funcionariam no contexto de seu estilo de performance porque não guardavam elementos necessários à espontaneidade de improvisação.

Como Evans compunha? Em uma entrevista em setembro de 1975, quando Don BACON (1994) Ihe perguntou se suas composições eram espontâneas ou se ele gastava horas no piano trabalhando-as, ele disse que ambos os pressupostos estavam corretos. Por exemplo, Peri's scope e My Bells surgiram de repente na sua cabeça e ele as esboçou diretamente em uma folha pautada. Outras vezes ele escrevia primeiro a harmonia e, depois, a melodia, como foi o caso de Time remembered. Às vezes, se assentava ao piano e trabalhava seguidamente, fazendo mudanças até ficar satisfeito, como ocorreu com Turn out the stars e Waltz for Debby.

Evans desenvolveu um estilo particular, próprio, e optou por não modificá-lo apenas pela obrigação de uma mudança estilística. Miles Davis reinventou a si mesmo várias vezes, mas Evans não era assim. Gostava de continuar viajando nos caminhos que abriu. Uma vez descoberta uma trilha, não buscava descobrir outros horizontes, mas compreender, refinar e explorar seu trabalho dentro daquele estilo (SHADWICK, 2002, p.79). Evans gostava de tocar e compor aquilo que lhe desse prazer de ouvir. Em uma entrevista para Marian Mc PARTLAND (1978) na Piano Jazz Series, ele disse que fazia música para se agradar e aperfeiçoar sua arte. Não se preocupava particularmente em se tornar popular. Se isso fosse acontecer, seria uma decorrência de suas convicções. Esta postura se refere tanto às suas composições quanto às suas performances. McPartland resume sua maneira de ser no mundo do jazz dizendo que ele "nadava contra a corrente".

Vários fatores são centrais para compreender as composições de Evans. Em primeiro lugar, elas são muito lógicas (PETTINGER, 1998, p.129). Embora muitos eventos ocorram simultaneamente em suas obras e elas possam transitar por muitos ou todos os 12 centros tonais, sempre retornam ao ponto de partida. 0 ouvinte as percebe como obras tonais e certamente não avant-garde, embora as estruturas harmônicas dos acordes sejam quase sempre inesperadas. Isso ocorre principalmente devido à uma abordagem planejada das estruturas musicais. Evans buscava uma compreensão clara e completa do arcabouço teórico do processo harmônico de qualquer peça em que estivesse trabalhando (Mc PARTLAND, 1978). Tornou-se famoso por estudar horas e horas as estruturas harmônicas dos standards do jazz que queria incluir no seu repertório. Esta mesma atenção à harmonia ele também revela nas suas composições. Evans precisava ser analítico para construir suas próprias obras (EVANS e EVANS, 2004). Uma prática muito comum no jazz é criar uma nova melodia sobre uma progressão harmônica de outro compositor. Embora compreendesse bem este conceito primordial enquanto pianista, Evans nunca utilizou esse recurso como compositor (REILLY, 1993, p.v). Tudo em suas composições é original e único.

\section{5 - 0 estilo composicional de Bill Evans}

A tabela no Ex.2 traz os títulos e os seguintes elementos das 19 obras instrumentais selecionadas de Bill Evans e analisadas no presente estudo: (1) título, (2) gravação mais antiga da peça ou copyright, (3) estilo/andamento, (4) métrica, (5) tonalidade, (6) forma, e (7) duração. Já 


\begin{tabular}{|c|c|c|c|c|c|c|c|c|c|c|c|c|c|c|c|c|c|c|c|}
\hline 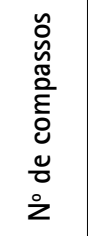 & నี & 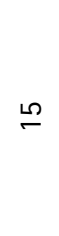 & $\approx$ & $\simeq$ & $\stackrel{\infty}{m}$ & $\stackrel{\infty}{m}$ & $\stackrel{d}{N}$ & & $\stackrel{\infty}{q}$ & & $\stackrel{\infty}{q}$ & q & ఫే & $\stackrel{\mathscr{N}}{2}$ & q & $\bowtie$ & กิ & q & $\stackrel{\infty}{\sim}$ \\
\hline 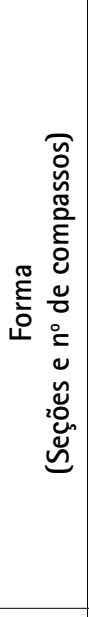 & 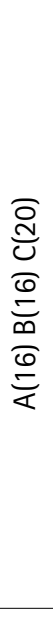 & 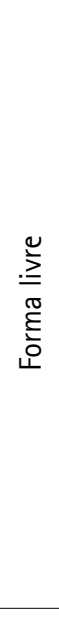 & 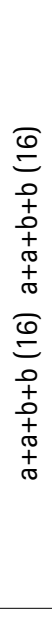 & 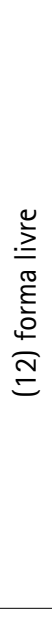 & 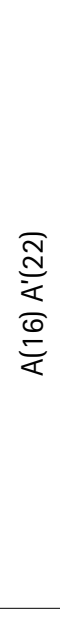 & 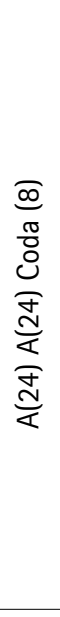 & 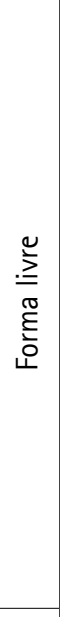 & 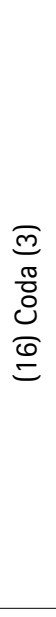 & 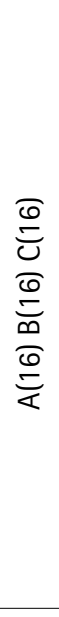 & 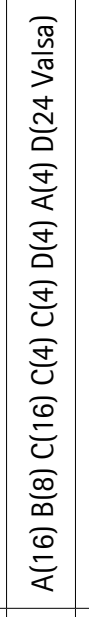 & 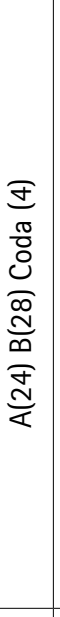 & 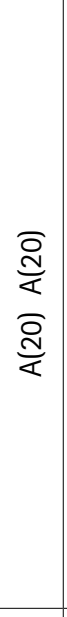 & 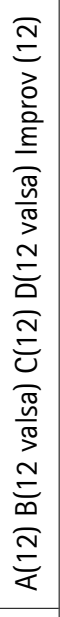 & 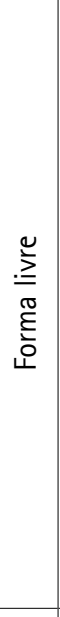 & 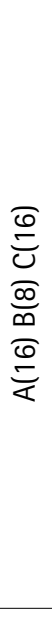 & 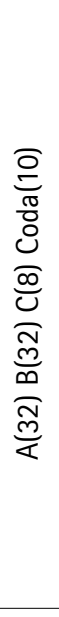 & 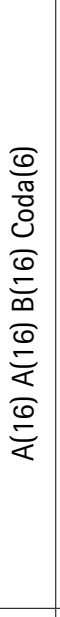 & 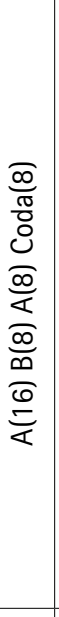 & 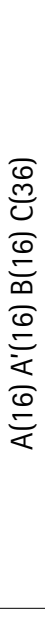 \\
\hline 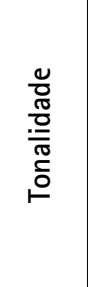 & ì & $\begin{array}{l}\frac{\overline{0}}{\sum^{\pi}} \\
\frac{0}{\sum} \\
\dot{\Sigma}\end{array}$ & à & $\sum_{i=0}^{\grave{j}}$ & 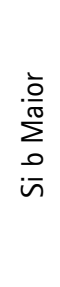 & 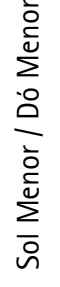 & 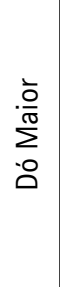 & $\sum_{\substack{\frac{0}{\pi} \\
.0}}$ & $\frac{. \overline{0}}{\sum_{i \pi}^{\pi}}$ & 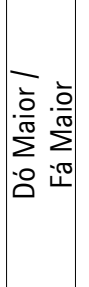 & 浐 & 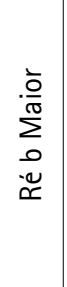 & 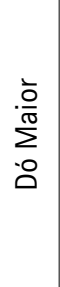 & 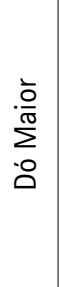 & : & 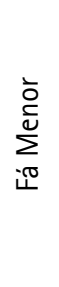 & : & 嵩 & $\sum_{i \pi}^{\frac{.}{\pi}} \sum_{i \pi}^{\pi}$ \\
\hline 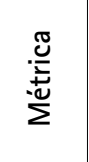 & $\frac{\partial}{\partial}$ & $\frac{\partial}{\partial}$ & $\frac{\partial}{\partial}$ & $\frac{\partial}{\partial}$ & $\frac{d}{\partial}$ & $\frac{d}{\partial}$ & $\frac{d}{a}$ & $\frac{d}{a}$ & $\frac{\partial}{\partial}$ & $\begin{array}{l}\frac{d}{m} \\
o \\
\frac{\partial}{\sigma}\end{array}$ & $\frac{d}{\partial}$ & $\frac{d}{a}$ & $\begin{array}{l}\frac{\partial}{m} \\
0 \\
\frac{\partial}{\gamma}\end{array}$ & $\frac{d}{\partial}$ & $\frac{\partial}{\partial}$ & $\frac{\partial}{m}$ & $\frac{j}{m}$ & $\frac{\partial}{\partial}$ & $\begin{array}{l}\frac{\sigma}{\sigma} \\
\frac{\dot{\Delta}}{m}\end{array}$ \\
\hline 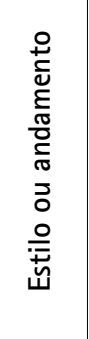 & 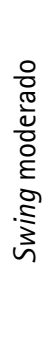 & 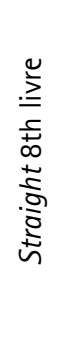 & 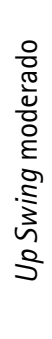 & 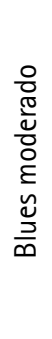 & $\begin{array}{l}\frac{\pi}{0} \\
\frac{\pi}{0} \\
\frac{0}{0} \\
0 \\
\frac{1}{E} \\
\frac{\pi}{0} \\
\frac{\pi}{\pi} \\
\frac{\pi}{\pi}\end{array}$ & 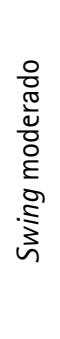 & 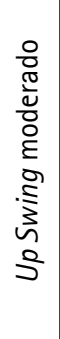 & 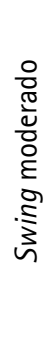 & 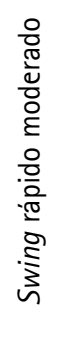 & 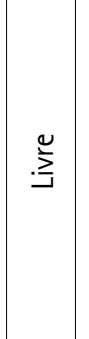 & 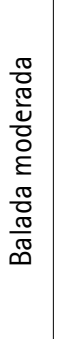 & 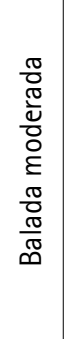 & $\begin{array}{l}\frac{\pi}{0} \\
\frac{\pi}{\pi} \\
\frac{\pi}{0} \\
0 \\
\frac{\delta}{E} \\
\frac{\pi}{0} \\
\frac{\pi}{\pi} \\
\varnothing\end{array}$ & 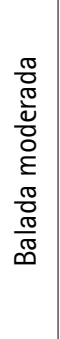 & 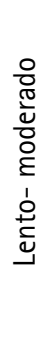 & 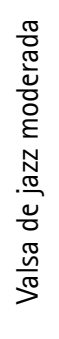 & 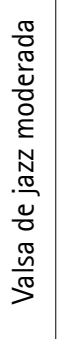 & 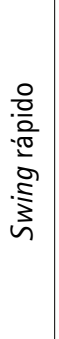 & 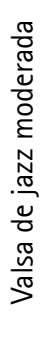 \\
\hline
\end{tabular}

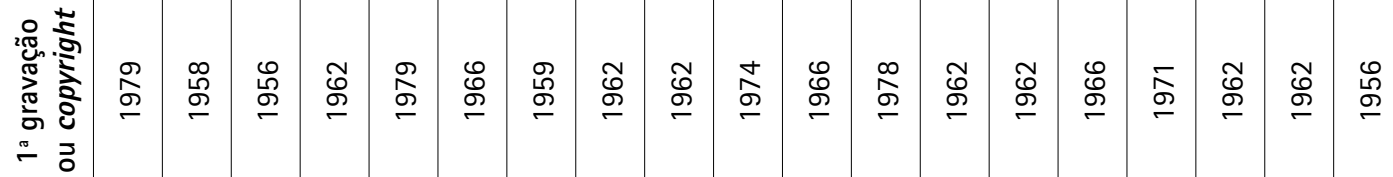

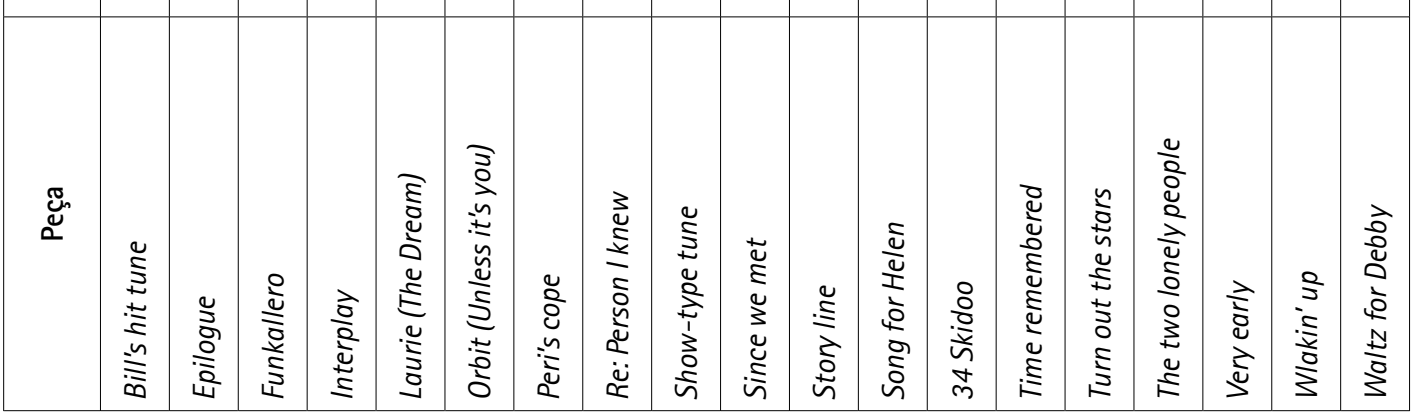


a tabela no Ex.3 traz (1) o ritmo harmônico de cada peça, (2) linguagem harmônica e (3) um resumo de suas caracteristicas principais.

A coleção mais completa de partituras das composições de Bill Evans é o Bill Evans fake book (Ludlow Music), transcrito e editado por Pascal WETZEL (2003) a partir das gravações de Bill Evans. Este livro, que é utilizado aqui como fonte primária, contem 55 canções originais juntamente com versões com letra de 16 delas. Durante sua carreira, apenas 52 dessas 55 canções foram gravadas. Ao editar as lead sheets, Wetzel utilizou principalmente as lead sheets originais ou publicadas, mas recorreu às gravações quando necessário, especialmente as gravações mais recentes para mostrar a evolução de Bill Evans no tempo. Devido ao grande interesse de Bill Evans pelos detalhes harmônicos, Wetzel foi bem mais preciso e detalhado do que normalmente se vê nas lead sheets, adicionando linhas de contraponto, codas e extensões de acordes, incluindo acordes de passagem e acordes alternativos. As tonalidades originais forma mantidas, embora o leitor deva saber que era prática de Evans tocar a mesma peça em outros tons, pois a transposição era uma de seus procedimentos musicais favoritos (WETZEL, 2003).

\begin{tabular}{|c|c|c|c|}
\hline Peça & $\begin{array}{c}\text { Ritmo harmônico } \\
\text { (acordes por c.) }\end{array}$ & Linguagem harmônica & Características principais \\
\hline Bill's hit tune & 1 por c. & ii $-V-I$ & Seção C repete 13 c. da Seção A \\
\hline Epilogue & 1 por $\mathrm{c}$. & & Forma livre \\
\hline Funkallero & 1 por c. & $\begin{array}{l}\text { ii - V - I } \\
\text { Dó Menor (nas frases "a") e Lá b Maior (nas frases "b") }\end{array}$ & Sub-seções a-a-b-a \\
\hline Interplay & 1 por $\mathrm{c}$. & Progressão de blues em Fá Menor & Sem frases repetidas \\
\hline Laurie (The Dream) & Moderato & $\begin{array}{l}\text { Círculo das } 5 a s \\
\text { ii }-\mathrm{V}-\mathrm{I}\end{array}$ & Forma livre \\
\hline Orbit (Unless it's you) & 2 por c. & Círculo das $5 a s$ & Contorno melódico destacado \\
\hline Peri's cope & 2 por c. & $\begin{array}{l}\text { ii }-\mathrm{V}-\mathrm{I} \\
\text { Dominantes secundárias }\end{array}$ & Forma livre \\
\hline $\begin{array}{l}\text { Re:Person } \\
\text { I knew }\end{array}$ & Lento & $\begin{array}{l}\text { Predomínio de acordes menores ou acordes menores } \\
\text { com } 7^{\mathrm{a}} \mathrm{M} \\
\text { Sem padrão harmônico }\end{array}$ & $\begin{array}{c}\text { Forma livre } \\
\text { Interpretação melódica livre }\end{array}$ \\
\hline Show-type tune & 2 por c. & $\begin{array}{l}\mathrm{ii}-\mathrm{V} \text { e } \mathrm{ii}-\mathrm{v} \\
\text { Harmonia complexa }\end{array}$ & $\begin{array}{c}\text { Forma livre Mudanças de } \\
\text { andamento }\end{array}$ \\
\hline Since we met & 1 ou 2 por c. & Círculo das 5as & $\begin{array}{c}\text { Forma livre Seção C repete } 11 \text { c. } \\
\text { da Seção A }\end{array}$ \\
\hline Story line & 1 por c. & $\begin{array}{l}\text { Centros tonais de Dó Maior, Sol Menor, Fá Menor e } \\
\text { Dó Menor }\end{array}$ & Forma livre \\
\hline Song for Helen & 1 por nota & $\begin{array}{l}\text { Círculo das 5as } \\
\text { Dominantes secundárias }\end{array}$ & Forma livre \\
\hline 34 Skidoo & 1 ou 2 por c. & $\begin{array}{l}\text { Harmonia complexa } \\
\text { Notas pedal }\end{array}$ & $\begin{array}{c}\text { Forma livre } \\
\text { Improvisação solo }\end{array}$ \\
\hline Time remembered & 1 por $\mathrm{c}$. & $\begin{array}{l}\text { Somente acordes maiores e menores } \\
\text { Harmonia complexa } \\
\text { Uso parcial do círculo das 5as }\end{array}$ & Forma livre \\
\hline Turn out the stars & 2 por c. & $\begin{array}{l}\text { Círculo das } 5 \text { as } \\
\text { ii }-\mathrm{V}-\mathrm{I} \\
\text { Dominantes secundárias }\end{array}$ & Forma livre \\
\hline The two lonely people & 1 por $\mathrm{c}$. & $\begin{array}{l}\text { V-I } \\
\text { ii - V } \\
\text { Trítonos }\end{array}$ & Forma livre \\
\hline Very early & 1 ou 2 por c. & $\begin{array}{l}\text { Harmonia complexa } \\
\text { Uso parcial do círculo das } 5 \text { as }\end{array}$ & ----- \\
\hline Wlakin' up & 2 por c. & $\begin{array}{l}\text { Acordes de A7 Maj e modo Lídio } \\
\text { Acordes de B m e modo Dórico }\end{array}$ & Padrão rítmico repetitivo \\
\hline Waltz for Debby & 1 por c. & $\begin{array}{l}\text { Harmonia complexa } \\
\text { Baixo cromático descendente } \\
\text { Harmonia relevante nas vozes internas }\end{array}$ & $\begin{array}{c}\text { Forma livre } \\
\text { Seção A' repete } 11 \text { c. da Seção A } \\
\text { Seção C repete } 10 \text { c. da Seção A }\end{array}$ \\
\hline
\end{tabular}

Ex.3 - Tabela com o ritmo harmônico, harmonia e resumo das principais características das 19 peças selecionadas de Bill Evans. 
Embora tivesse uma técnica exemplar, Bill Evans não a utilizava para impressionar o público ou dar vazão a mero virtuosismo. Seu foco estava no conteúdo musical e na expressão que pretendia comunicar (LEES, 1988, p.148). Boa parte da música que compunha era para suas próprias performances e não para os outros tocarem. Era considerado um mestre das valsas de jazz. As interpretações de suas baladas eram lendárias. Embora tocasse blues, não era conhecido como pianista de blues ou compositor influenciado por este gênero. Isto pode ser comprovado na análise de gênero de suas obras, como mostra a tabela no Ex.4.

\begin{tabular}{|c|c|}
\hline Gênero & No de obras (55) \\
\hline Valsa de Jazz & 10 \\
\hline Balada & 16 \\
\hline Medium swing & 8 \\
\hline Medium up swing & 9 \\
\hline Fast swing & 3 \\
\hline Blues & 2 \\
\hline Outros gêneros & 7 \\
\hline
\end{tabular}

Ex.4 - Tabela com incidência de gêneros nas composições instrumentais de Bill Evans.

Seu foco entre os andamentos lentos e moderados abriu espaço para desenvolver características que prezava muito, como lirismo, sonoridade e variedade harmônica. Duas de suas peças mais conhecidas são valsas: Very early e Waltz for Debby. Duas outras das mais conhecidas são baladas: Time remembered e Turn out the stars, cuja popularidade atesta a preferência de seu público por esse gênero. Já as duas peças na forma do blues são do início de sua carreira (WETZEL, 2003, Discography, p.110.) e apenas uma foi gravada, o que revela seu distanciamento deste gênero. Apenas três peças - Displacement, One for Helen e Fun ride - tem a notação de fast swing, 0 que mostra um movimento contrário a uma tendência observada em muitos de seus contemporâneos.

Ao compor, Evans gostava de usar a métrica 3/4 "para articular o lado mais delicado e reflexivo de sua personalidade artística" (SHADWICK, 2002, p.174). É interessante notar que a maioria das valsas foi dedicada às mulheres que fizeram parte de sua vida. Evans também gostava de mudar a métrica no meio da música, como em Comrade Conrad, Five, Since we met e 34 Skidoo. A mudança na métrica o permitia mudar a atmosfera da música subitamente. Waltz for Debby é uma valsa de jazz, mas ele também a tocava e a gravou em 4/4.

A forma musical é um elemento crucial na improvisação do jazz, especialmente para manter o grupo tocando junto e coeso. Quando um grupo está improvisando sem precisar ler a partitura, a consciência da forma musical ajuda os músicos a se orientarem e interagirem. As formas mais comuns em jazz são o blues de 12 compassos e duas outras formas comumente encontradas no Great American songbook of standards: $A A B A$ e $A B A B$, sendo que as seções $A$ e $B$ tem 8 compassos cada. Em muitos standards, a melodia e a harmonia das Seções A permanecem as mesmas ou são muito semelhantes entre si no esquema AABA. A mesma redundância ocorre com as Seções $A$ e $B$ na forma $A B A B$. No caso de Bill Evans, a maioria de suas canções não segue melodica ou harmonicamente essas formas tradicionais. Somente These things called changes, a qual toma emprestado como base os chord changes de What is this thing called love $\mathrm{e}_{1}$ mesmo assim, não segue a forma AABA ao pé da letra.

A forma de 32 compassos é também pouco provável de ser encontrada entre as canções de Bill Evans. Apenas 4 delas tem exatamente 32 compassos, mas nenhuma delas se conforma com os modelos tradicionais quanto à duração de cada seção interna da forma. Não há uma duração comum em suas composições; elas variam de 12 a 80 compassos. Quanto às seções internas, muitas têm 16 compassos, mas esta extensão não deve ser tomada como padrão, pois apenas 18 das peças analisadas apresentam esta característica. De uma maneira geral, em relação à forma, não se observa um traço comum nas suas composições, como atesta, de maneira mais detalhada, a tabela do Ex.2 acima.

Do ponto de vista da melodia, 48 das 55 canções do fake book de Evans podem ser consideradas de forma livre, uma vez que as melodias não se repetem ao longo da composição. Naquelas em que parte da melodia é repetida, é muito improvável que a melodia seja repetida com exatidão na seção seguinte. Por exemplo, em Bill's hit tune, a forma é A (16c.) B (16c.) C (20c.) na qual os 13 primeiros compassos de $C$ são os 13 primeiros compassos de $\mathrm{A}$. Se checarmos a existência de repetição melódica nas seções dentro das peças, se observa pouca ou nenhuma repetição de frases dentro das próprias seções. Melodicamente, cada nota está presa ou é dependente da harmonia, o que varia muito no caso de Bill Evans(PETINGER, 1998, p.180).

$\mathrm{Na}$ maioria das lead sheets que os músicos de jazz utilizam, frases de 4 ou 8 compassos são as mais comuns e suas improvisações refletem estes padrões. $\mathrm{Na}$ sua performance, Evans pensa em frases maiores, de 32 compassos ou mais (LEES, 1998, p.151). A forma livre de suas composições reflete esta característica. Muitas vezes, é difícil identificar onde começam e onde terminam suas frases. Chuck ISRAELS (1985, p.112), um de seus contrabaixistas, diz que "suas frases começam e terminam cada hora em um lugar, geralmente cruzam os limites entre uma seção e outra".

Em composições de jazz e, por conseguinte, improvisações de jazz, a armadura de clave é uma boa indicação do centro tonal ou modal de uma peça. A natureza melancólica observada em boa parte de sua música sugere, em princípio, uma grande utilização de tonalidades menores. 


\begin{tabular}{|c|c|c|}
\hline Centro tonal & Tom menor & Tom maior \\
\hline Dó & 6 & 19 \\
\hline Ré bemol & - & 3 \\
\hline Ré & 1 & 4 \\
\hline Mi bemol & 3 & - \\
\hline Mi & - & 1 \\
\hline Fá & 6 & - \\
\hline Sol bemol & - & 4 \\
\hline Sol & 1 & 2 \\
\hline Lá bemol & - & 1 \\
\hline Lá & - & 3 \\
\hline Si bemol & 2 & 1 \\
\hline Si & - & \\
\hline
\end{tabular}

Ex.5 - Tabela com tonalidades das composições de Bill Evans.

Mas são apenas 14 em um total de mais de 50. Na sua entrevista a Marian Mc PARTLAND (1978), ele fala sobre duas de suas tonalidades preferidas: Lá Maior e Mi Maior, ressaltando a ressonância de seus harmônicos que lhes é característica. Mas ele parece se contradizer, uma vez que apenas uma peça, Remembering the Rain, é em Lá Maior e nenhuma é em Mi Maior! (Ex.5)

Observando o Ex.5 acima, poderiamos pensar que Dó Maior é sua tonalidade favorita, ou que a maioria de suas músicas é em Dó Maior ou, ainda, que Dó Maior é a tonalidade predominante em suas improvisações. Entretanto, ao examinarmos de perto suas composições, vemos que suas harmonias raramente permanecem em um centro tonal ou, mesmo, em tonalidades vizinhas. Utilizar o termo centro tonal aqui é mais apropriado porque é difícil perceber uma clara mudança de tonalidade na música de Evans. É mais fácil perceber uma mudança de centro tonal. A armadura indica apenas um ponto de partida e, às vezes, o ponto final, pois é comum para ele acabar em outra tonalidade. Por exemplo, o primeiro acorde e a tonalidade de Very early é Dó Maior, mas o último acorde da música é Si Maior. Já Time remembered também começa em Dó Maior, mas termina em Dó menor. Assim, os centros tonais primários nas composições de Bill Evans são difíceis de serem determinados. Assim, a armadura de clave pode ser um elemento enganoso.

Quando as pessoas se perguntam sobre a música de Evans, uma questão central é a existência de uma característica harmônica recorrente no seu estilo. Dois aspectos são importantes nessa busca: o ritmo harmônico dos acordes (ou o número de mudanças de acordes por compasso) e a existência de padrões harmônicos, como a progressão ii - V - I ou o círculo das quintas.

Bill Evans era conhecido por gastar horas trabalhando as progressões harmônicas para ter certeza de obter os voicings (condução de linhas melódicas dentro das vozes dos acordes) desejados. As vozes internas e a condução de vozes eram fundamentais, caso quisesse imprimir um fluxo harmônico mais rápido. A complexidade harmônica de uma peça pode ser determinada observando-se a frequência de mudança de seus acordes. A tabela do Ex.6 mostra os padrões de mudança de acordes nas músicas selecionadas de Evans em que isso ocorre claramente. Isto revela padrões comuns à maioria do repertório de jazz no Great American standard songbook.

\begin{tabular}{|c|c|}
\hline Acordes por compasso & $\begin{array}{c}\text { Número de } \\
\text { composições }\end{array}$ \\
\hline 1 & 14 \\
\hline 1 ou 2 & 14 \\
\hline 2 & 20 \\
\hline 3 ou 4 & 2 \\
\hline
\end{tabular}

Ex.6 - Tabela com padrões de mudança de acordes nas músicas de Bill Evans

A principal diferença entre a música de Bill Evans e a de outros jazzistas reside na qualidade dos acordes e para onde ele se dirigem. Dois padrões bastante comuns na literatura do jazz são o ii - V - I (ou i) ou o I - vi - ii - V - I (que são progressões também chamadas de rhythm changes no meio jazzístico). Se o padrão ii - V - I aparece muito no repertório de jazz, não é um padrão que Bill Evans utiliza com frequência, se restringindo, no nosso caso, às músicas Bill's hit tune, Turn out the stars e The Two lonely people, o que revela uma utilização menos frequente ainda na sua fase mais madura.

Dois procedimentos harmônicos são frequentes no seu estilo: a utilização do círculo das $5^{\text {as }}$ e as dominantes secundárias, que aparecem extensivamente em 25 de suas composições. Um bom exemplo são os seis primeiros compassos de Turn out the stars, cuja progressão harmônica a seguir ${ }^{1}$ quase conclui um ciclo completo (Ex.7). 


\section{círculo das 5 as \\ Medium Ballad quase completo}
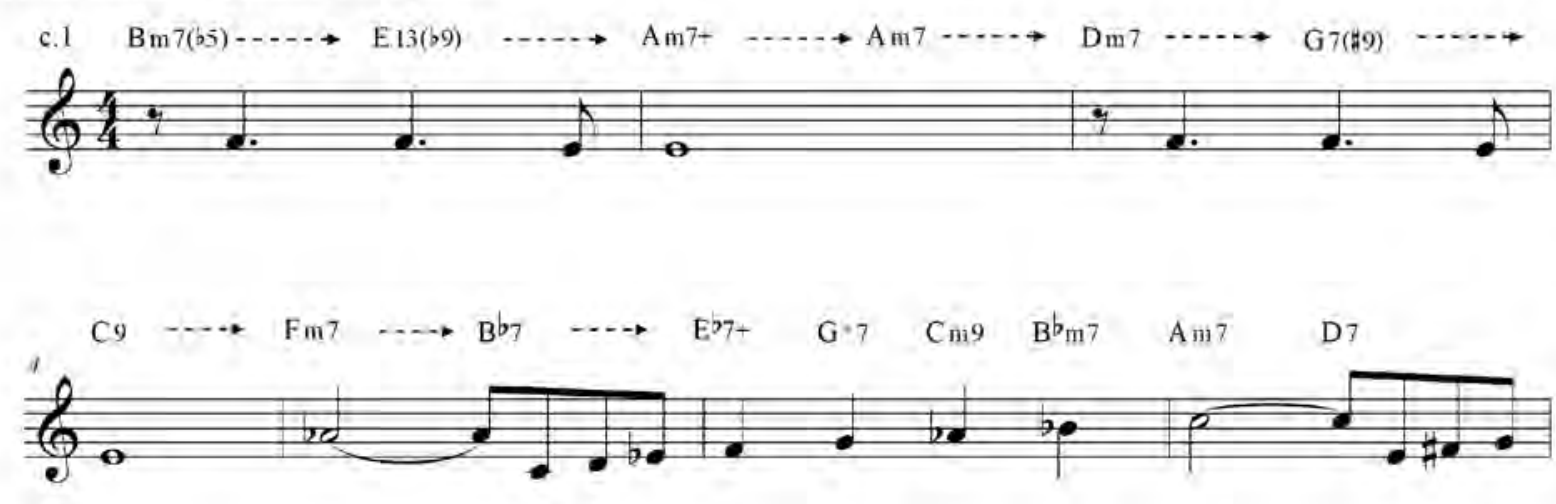

Ex.7 - Círculo das $5^{\text {as }}$ quase completo em Turn out the stars de Bill Evans (exemplo musical elaborado a partir da lead sheet de WETZEL, 2003, p.80).

Seu emprego frequentemente difere do padrão de círculo das $5^{\text {as }}$ do padrão ii - V - I. Não é sempre que a qualidade dos acordes segue o padrão tradicional (acorde menor / dominante / acorde maior), como acima. Outro exemplo aparece em Time remembered, no qual cada acorde dura um compasso:

\section{| Am9 / Dm9 | Gm7 / Cm7 | Fm9 |}

Outro exemplo pode ser extraído dos c.13-20 de Waltz for Debby, que tem a seguinte progressão:

\section{| Am7 | Dm7 | Gm7 | C7 | Am7 | Dm7 | Gm7 | C7 |}

Essas progressões, retiradas de suas peças mais conhecidas representam bem os padrões do círculo das quintas não tradicionais de Evans. A utilização de dominantes secundárias é outro procedimento composicional característico, essencial para que ele transite por diferentes centros tonais (Mc PARTLAND, 1978). Very early, sua primeira composição revela a importância deste conceito na sua música. Na sequencia de 16 acordes (um por compasso) da Seção A desta peça (na qual as dominantes secundárias estão grifadas), há cinco encadeamentos $\mathrm{V} \square \mathrm{I}$ (ou i), procedimento que aparece também em muitas outras músicas de Evans:

/ Cmaj7 / Bb9 / Ebmaj7 / Ab7(\#9) / Dbmaj7 / G7 / Cmaj7 / Bb9(b5) / Dmaj7 / Am7 / F\#m7 /B7(b9) / Em7 | Ab7 / Dbmaj7 | $\underline{G+7}$ |

Outro procedimento, a estruturação harmônica pelo círculo das 5as também lhe permite explorar rapidamente muitos centros tonais, não raro, passar pelos 12 centros tonais. Dois exemplos de composições em que Evans faz todo este percurso são Comrade Conrade Fun ride. Mesmo que a função dos acordes possa ser modificada ou, ainda, que ele acrescente diversas alterações ou extensões [ou "tensões", como se diz no Brasil], a função Dominante Tônica com acordes em estado fundamental faz com que a música soe claramente tonal e não o que um ambiente harmônico cheio de alterações poderia sugerir. A presença das fundamentais dos acordes nos baixos sempre traz, em algum ponto, a sensação de retorno ao centro tonal.

Time remembered é exemplar na maneira de Evans utilizar harmonias não tradicionais. A peça utiliza apenas acordes menores e maiores, sem alterações e sem exercer a função de dominante. Em jazz, a função dominante é uma função básica, uma vez que é o acorde que pode mais facilmente ser alterado e o mais fácil de ser substituido, comum em procedimentos típicos do estilo que permitem colorir, tensionar e relaxar. Time remembered é praticamente uma aula de como utilizar, na improvisação, o modo Dórico em acordes menores e o modo Lídio em acordes maiores. Mesmo recorrendo a somente estes dois modos, Evans ainda consegue a tensão e relaxamento desejados.

Chuck Israels afirma que as harmonias de Evans eram menos dependentes de acordes do que da "sobreposição de linhas contrapontísticas nas quais a fase de tensão e relaxamento entre a melodia e as vozes secundárias era sutilmente atenuada pelo seu controle do toque pianístico" (ISRAELS, 1985, p.110). Este comentário se relaciona diretamente com os procedimentos de Evans na condução de vozes, especialmente na distribuição das vozes internas. A progressão de acordes geralmente é bastante cromática, mas a tonalidade da música está sempre presente. 0 educador e pianista de jazz Tim MURPHY (2008), diz que a harmonia de Evans é sinônimo do baixo cifrado no mundo do jazz e que sempre traz surpresas. 
A construção rítmica era tão importante quanto a construção harmônica para Evans. 0 deslocamento rítmico e a sobreposição de ritmos binários ou ternários sobre a disposição dos acordes são particularmente relevantes na sua música (Mc PARTLAND, 1978). 0 educador e saxofonista de jazz Jeff ANTONIUK (2008) relata uma conversa que teve com o reconhecido saxofonista de jazz Joe Lovano. Em certa ocasião, Lovano teve a sensação de estar tocando atrasado em uma gig com Bill Evans, o que seria incomum para um músico tão experiente como ele. Só depois compreendeu que Evans estava, na verdade, antecipando as mudanças de acordes antes mesmo das antecipações típicas do "e" [como em: um, dois, três, quatro "e"...], ou seja, antes mesmo da colcheia antes dos tempos fortes. Lovana não estava de fato atrasado. Evans, na verdade, estava antecipando as mudanças de acordes para impactar os ritmos e a improvisação. Displacement, uma das composições de Evans, mostra claramente este conceito no qual a mudanças de acordes ocorrem no tempo 4 ao invés do tempo 1.

Outros tipos de deslocamentos rítmicos que ele utilizava ocorriam nas polirritmias e sugestão de métricas complexas. Esses procedimentos começam a aparecer em Peri's scope (PETTINGER, 1998, p.93), cuja escrita é em 4 / 4 mas tem a sensação métrica de um ternário 3 /4 (Ex.8).
0 conceito de alternar métricas pode ser observado em Five (que transita entre 4/4,5/4 e 3/4) e que também traz polirritmias diversas como 5 contra 2 e 5 contra 3 , mostradas no Ex.9.

Já em $G$ waltz, ele utiliza 4 contra 3 e 3 contra 2 . Em muitas outras peças ele emprega rítmicas de 3 contra 2 conjugadas com antecipações do tempo forte.

Evans foi um dos primeiros músicos de jazz a compor se baseando em séries dodecafôncias. Conhecedor da obra de Schoenberg, ele escreveu duas peças utilizando este conceito: Twelve tone tune, conhecida como T.T.T. e Twelve tone tune two, conhecida como T.T.T.T. Ele afirmou que o a inspiração para essas peças foi apenas o desafio da escrita, pois não utilizaria este conceito tendo o público em mente. Queria apenas ampliar suas habilidades de compositor (SHADWICK, 2002, p.151). T.T.T. tem apenas 12 compassos e 36 notas. Cada apresentação da série tem a duração de apenas 4 compassos (Ex.10).

Ao harmonizar a série, ele utilizou uma harmonia diatônica devido à dificuldade de improvisar sobre a série (La VERNE, 1990, p.8). Como diversos outros compositores pós-schoenberguianos, ele optou por flexibilizar a técnica serial, não seguindo a regra segundo a qual nenhuma nota poderia se repetida antes que
$\mathrm{Dm} 7$

c. 5

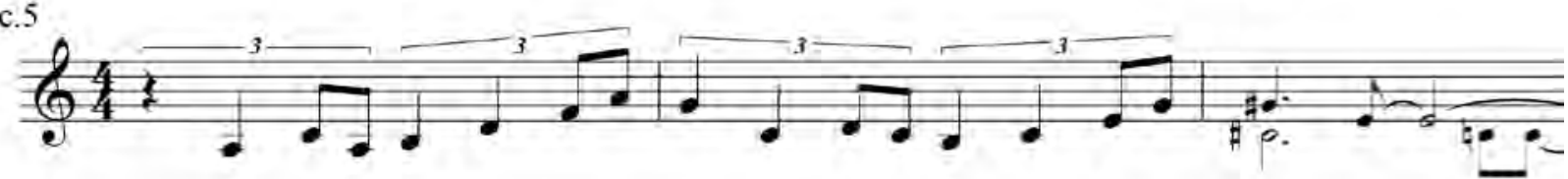

Ex.8 - Escrita ternária (3/4) dentro de métrica quaternária (4/4) em Peri's scope de Bill Evans (exemplo musical elaborado a partir da lead sheet de WETZEL, 2003, p.53).

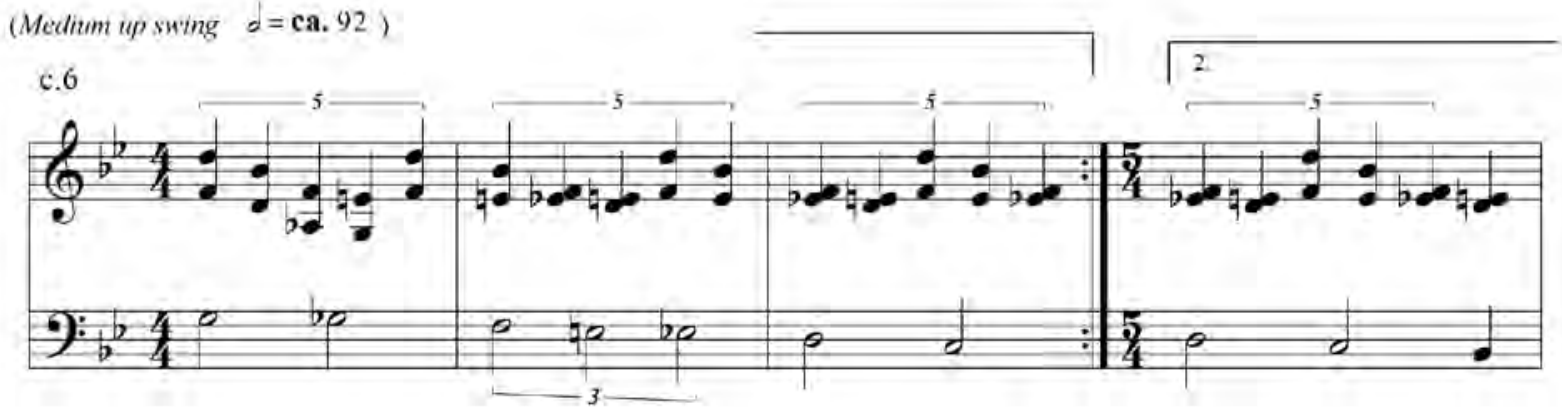

Ex.9 - Mudança de métrica e utilização de polirritmias em Five de Bill Evans (exemplo musical elaborado a partir da lead sheet de WETZEL, 2003, p.18). 

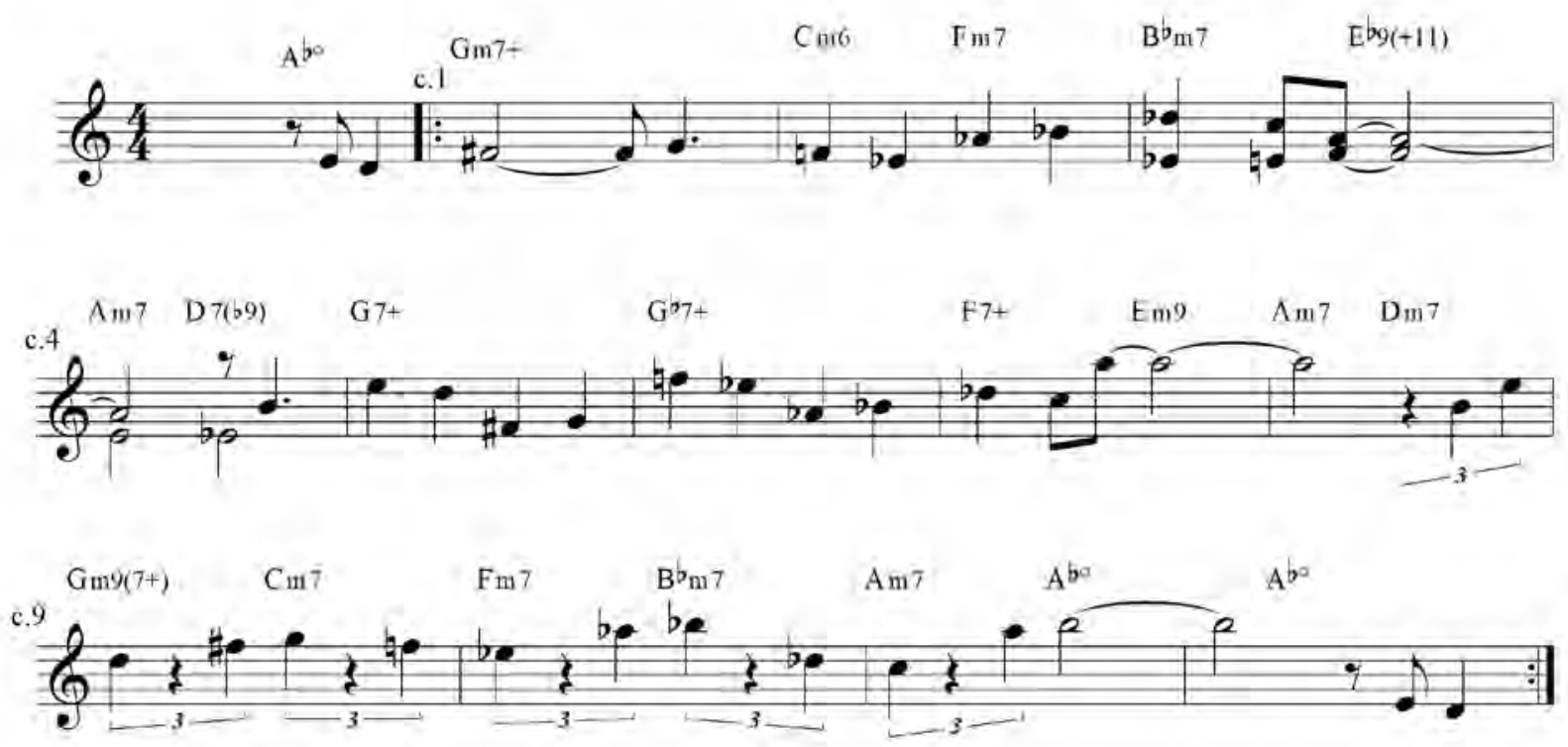

Ex.10 - Tema serial harmonizado de T.T.T. (Twelve tone tune) de Bill Evans (exemplo musical elaborado a partir da lead sheet de WETZEL, 2003, p.81).

todas as notas da série fossem apresentadas. Também não tentou evitar o conceito de tonalidade convencional para harmonizar a série. Ainda assim, improvisar sobre as séries nessas peças se mostrou uma tarefa bastante difícil (SHADWICK, 2002, p.151).

Em T.T.T.T. Evans expandiu o conceito de emprego da série dodecafônica para 60 notas, que ocorrem ao longo de 12 compassos e que, depois, se repete. Desta vez, a harmonização foi diferente de T.T.T. no sentido de se utilizar todos os acordes maiores, o que resultou em um encadeamento de 24 compassos para a improvisação:

$$
\begin{aligned}
& \text { / G / F / Eb / Db / C / Bb / Ab / Gb / B / Bb / A / Ab / } \\
& \text { / G / A / B / C\# / C / D / E / F\# / B / C / C\# / D / }
\end{aligned}
$$

o que também resultou em um desafio para os melhores improvisadores, mesmo em um andamento moderado (Ex.11).

Outra peça de Evans que revela a diversidade de seu estilo composicional é Fudgesicle built for four, escrita no início de sua carreira. 0 tema tem o procedimento inicial de uma fuga a quatro vozes, com entradas do sujeito para violão (Ex.12), piano (Ex.13), contrabaixo (Ex.14) e sax tenor (Ex.15). Embora o tema seja complexo, a improvisação é feita normalmente sobre o encadeamento harmônico.

Uma questão sobre o estilo composicional de Evans é perceber como se desenvolveu ao longo de sua carreira. Muitos aspectos das técnicas que aparecem em Very early, escrita enquanto ele ainda era aluno da Southeastern Louisiana College, aparecem em diversas composições de sua fase madura. Entretanto, dois aspectos se tornam cada vez mais refinados e frequentes: as progressões observadas nas vozes internas e uma abordagem mais sofisticada da construção rítmica e seus deslocamentos.

Todas as composições de Evans mostram sua habilidade de percorrer bem o caminho planejado e, ao mesmo tempo, obter grande variedade de técnicas composicionais. Em geral, suas obras exibem grande unidade, pois são construídas a partir de elementos básicos, como um pedal, um acorde estrutural, um padrão rítmico, um motivo de 3 ou 4 notas, uma mudança de andamento, uma relação entre tonalidades aparentemente distantes, séries dodecafôncias, entre outros. E resultam sempre desafiadoras, interessantes e complexas. Ao longo de toda sua vida, seu conceito de harmonia foi sendo gradualmente construído. Cada desenvolvimento preparava o terreno para um novo passo, como afirma seu biógrafo Peter PETTINGER (1998, p.174):

\footnotetext{
Este mundo essencialmente harmônico foi enriquecido por partes que se movem interna e externamente, comentários e coloridos: uma nota que começa como uma nota de passagem cromática se transfere para dentro do acorde, o qual emerge como parte de um novo voicing. A evolução o acompanhou até a sua morte.
}

Ao dizer que: ". . . toda música é romântica. .. o romantismo com disciplina é o mais bonito tipo de beleza" (TEACHOUT, 1998, p.47), Evans sintetizou seu estilo composicional. Essa disciplina, que intimamente ligava suas composições à sua maneira de improvisar talvez tenha contribuido para o fato de que muito poucas delas se tornaram composições que são tocadas por outros artistas de jazz (BIOGRAPHY RESOURCE CENTER, 2008). Embora a grande maioria de suas obras tenha melodias interessantes, é sua harmonia o que realmente a distingue, e que se reverte em desafios para os que se propõe a tocá-la. Parece haver 

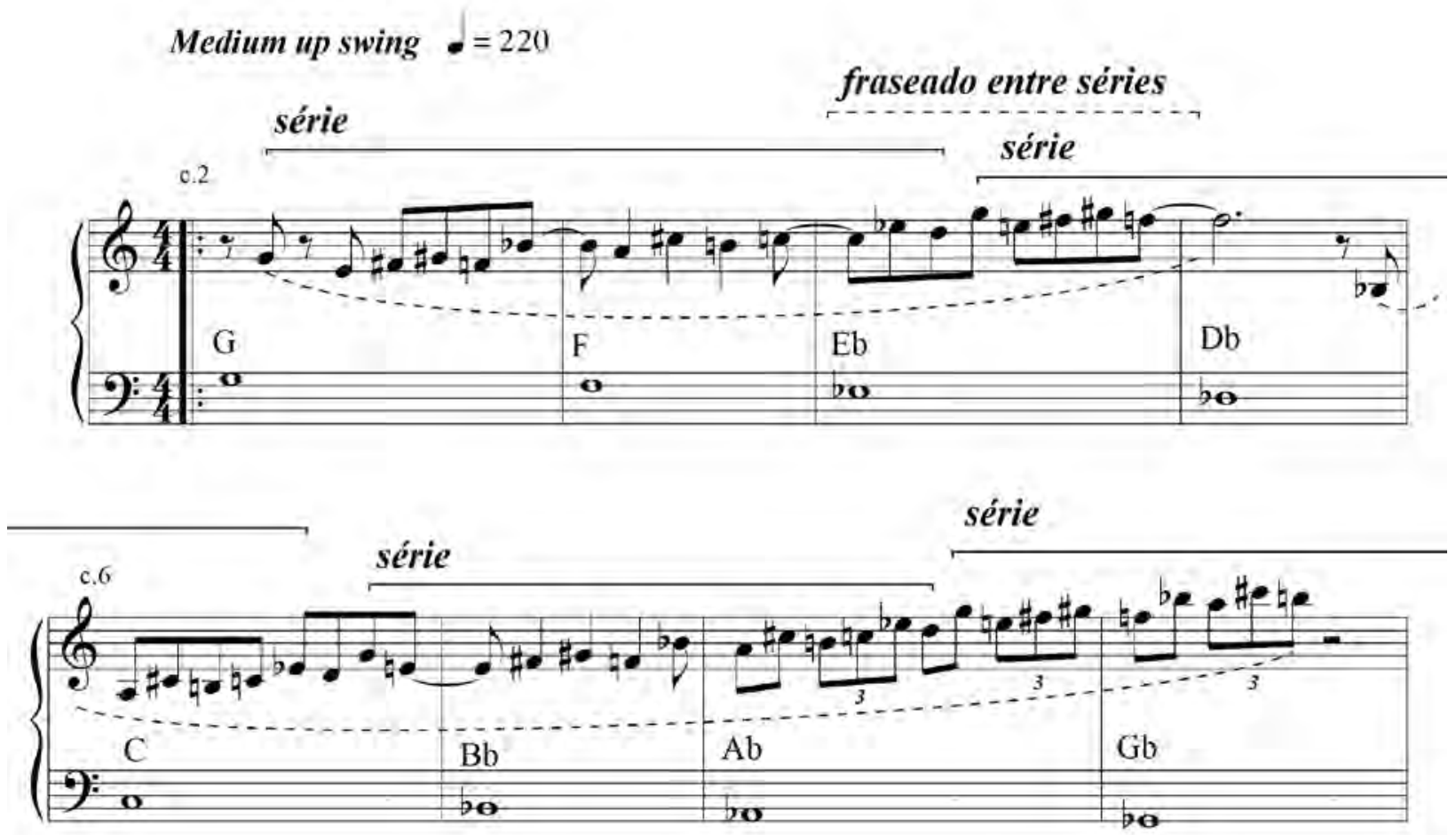

Ex.11 - T.T.T.T. (Twelve tone tune two) de Bill Evans, com 4 ocorrências da série em duas frases ascendentes (exemplo musical elaborado a partir da lead sheet de WETZEL, 2003, p.82).

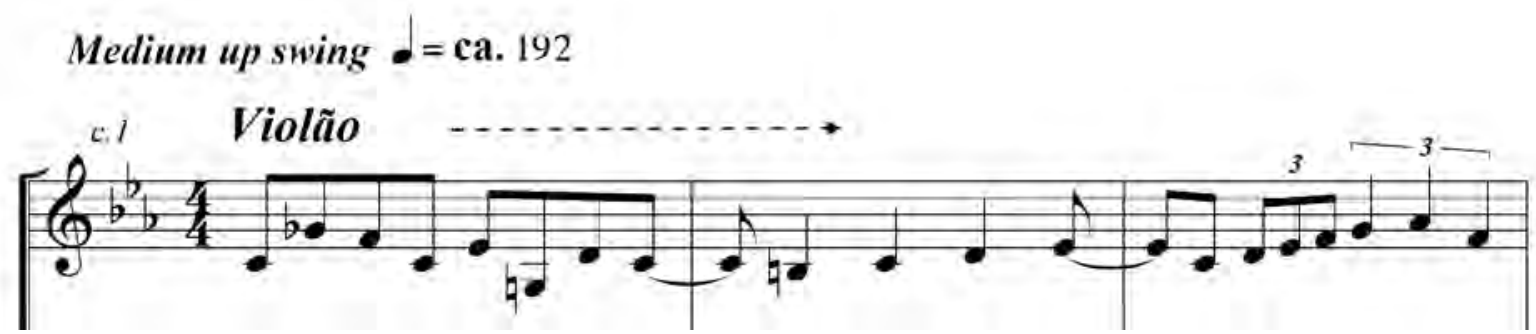

Ex.12 - Entrada do violão com o tema em fugato de Fudgesicle built for four de Bill Evans (exemplo musical elaborado a partir da lead sheet de WETZEL, 2003, p.23).

outra razão ainda mais forte do que a complexidade para o fato de ouvirmos tão pouco a música de Evans: a maioria dos músicos de jazz não gosta de tocar as notas como estão escritas. E esta prática não combina com a natureza dos temas de suas composições, que têm um grande sentido de completude melódica, harmônica e rítmica, o que levou Sean PETRAHN (1991, p.11) a dizer:

Ninguém precisa mudar uma única nota ou acorde nas canções de Bill Evans; você destruiria suas composições. Você mudaria um acorde em uma sonata de Beethoven ou nas "improvisações" de Bartok? Duvido. É preciso uma grande humildade para tocar a música de Bill Evans porque você precisa deixá-la soar sozinha; você deve deixar seu ego longe do instrumento e tocá-la como está escrito.
Eddie Gomez, que foi contrabaixista de Bill Evans por onze anos, fala sobre seu colega: "Bill Evans era articulado, decidido, gentil, majestoso, engraçado e sempre nos apoiava. Seu objetivo era fazer uma música que equilibrasse paixão e intelecto, que falasse ao coração" (PETTINGER, 1998, p.246). Bill Evans é considerado um dos pianistas mais influentes na história do jazz, mas seu papel como compositor ainda não foi bem avaliado. Espera-se que outros estudos sobre sua obra contribuam para que ocupe seu verdadeiro lugar. 0 lugar de um pianista extraordinário que foi também um compositor extraordinário. 


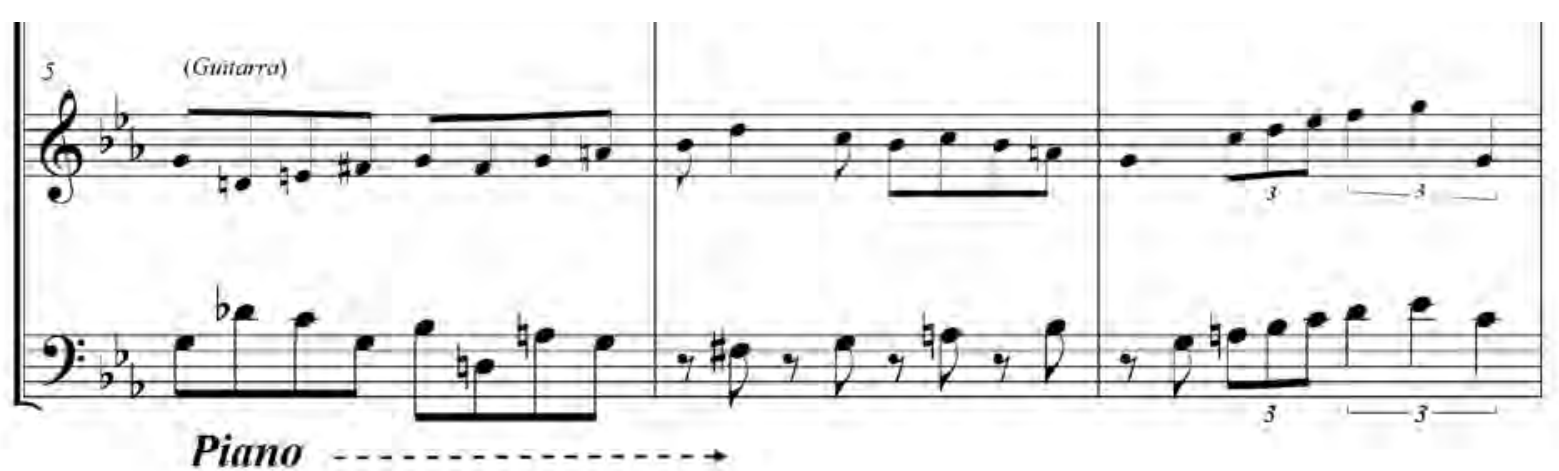

Ex.13 - Entrada do piano com o tema em fugato de Fudgesicle built for four de Bill Evans (exemplo musical elaborado a partir da lead sheet de WETZEL, 2003, p.23).

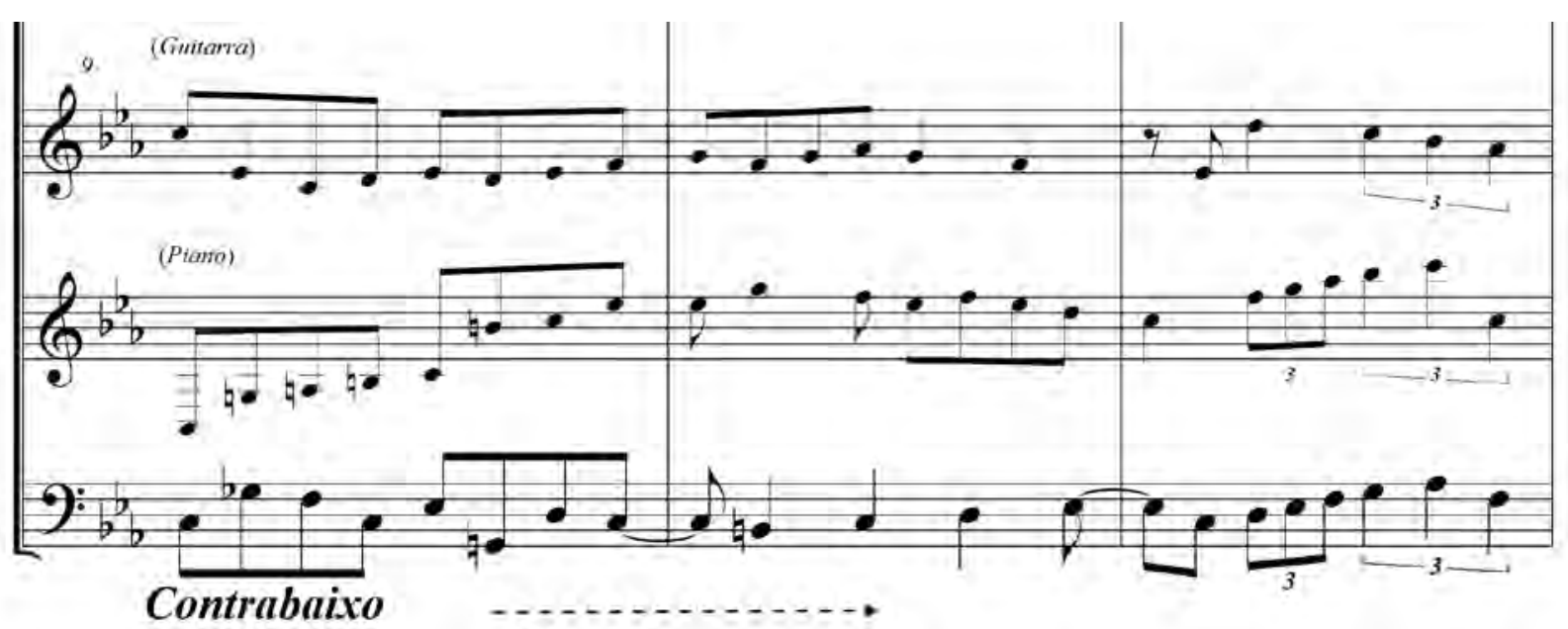

Ex.14 - Entrada do contrabaixo com o tema em fugato de Fudgesicle built for four de Bill Evans (exemplo musical elaborado a partir da lead sheet de WETZEL, 2003, p.23).

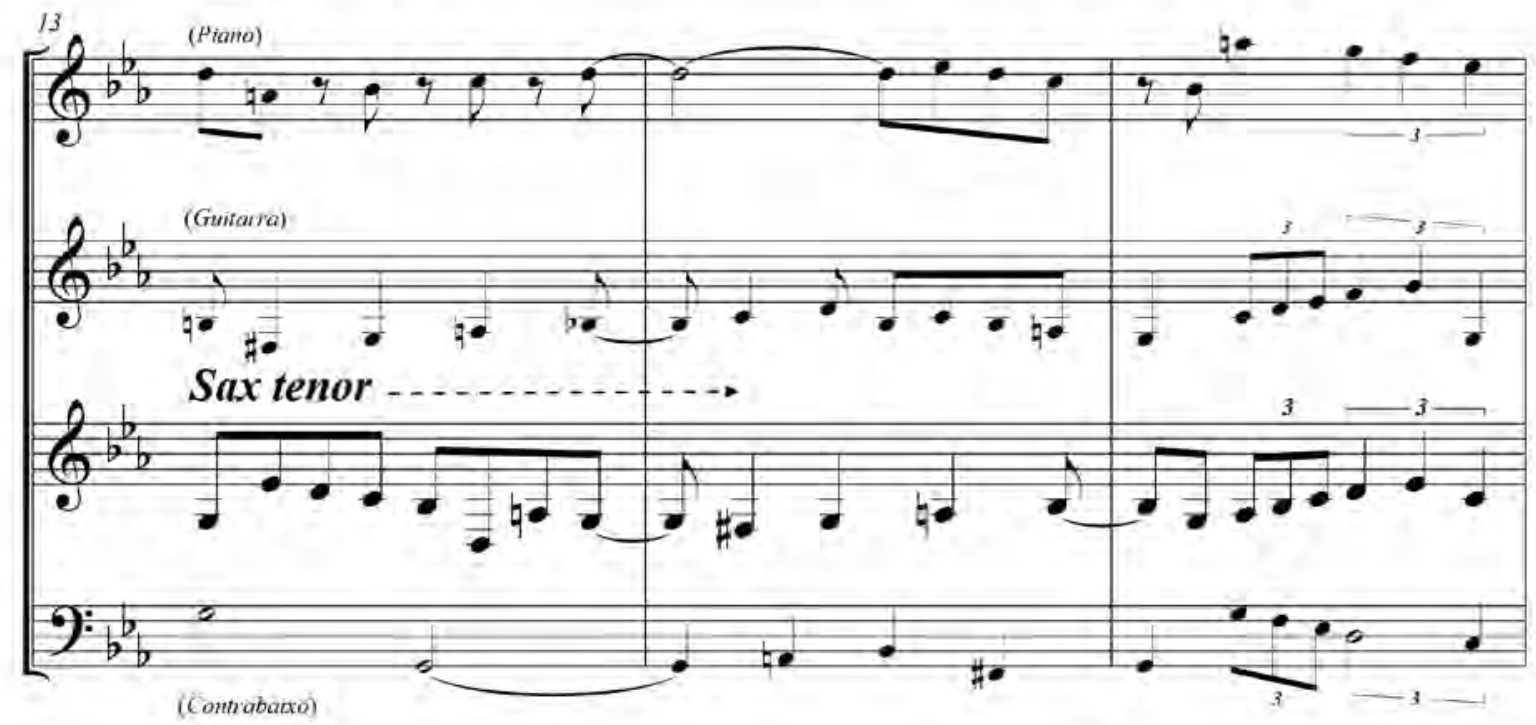

Ex.15 - Entrada do sax tenor com o tema em fugato de Fudgesicle built for four de Bill Evans (exemplo musical elaborado a partir da lead sheet de WETZEL, 2003, p.24). 


\section{Referências}

ANTONIUK, Jeff. Entrevista pessoal de Jeff Antoniuk a Bill Murray. 8 de Novembro, 2008.

BACON, Don. Interview with Bill Evans. In: Letter From Evans. v.5. n.2, winter, 1994. p.17-21.

BIOGRAPHY RESOURCE CENTER. Contemporary musicians: Bill Evans. v.17, Gale Research, 1996, reproduced in Biography Resource Center (Farmington Hills, Michigan: Gale, 2008).

COLLIER, James Lincoln. The Making of jazz: A Comprehensive History. New York: Dell Publishing, 1978.

DOERSCHUK, Robert L. 88: The Giants of jazz piano. San Francisco: Backbeat Books, 2001.

EVANS, Bill; EVANS, Harry. Bill Evans and Harry Evans: the universal mind of Bill Evans: Jazz Pianist on the Creative Process and Self-Teaching. Direção de Louis Carvell. Eforfilms, 2004 (DVD).

FEATHER, Leonard; GILTER Ira. The Biographical encyclopedia of jazz. New York: Oxford University Press, 1999.

ISRAELS, Chuck. Bill Evans (1929-1980): A Musical memoir. The Musical Quarterly. v.1, n.2, 1985. p.109-115.

La VERNE, Andy. Bill Evans' Twelve-Tone Tune. In: Letter From Evans. v.2, n.2. Nov./Decz, 1990. p.8-10.

LEES, Gene. Meet Me at Jim \& Andy's: jazz musicians and their world. New York: Oxford University Press, 1988.

LYONS, Len. The Great jazz pianists: speaking of their lives and music. New York: Quill, 1983.

Mc PARTLAND, Marian. Interviews with Bill Evans. In: Marian McPartland's Piano Jazz with Guest Bill Evans. The Jazz Alliance, TJA-12038-2, 1978 (vídeo).

MURRAY, J. William (Bill) Murray. Billy's touch: an analysis of the

compositions of Bill Evans, Billy Strayhorn, and Bill Murray. Towson, Maryland, EUA: Towson University: 2011 (Dissertação de Mestrado).

MURPHY, Tim. Entrevista pessoal de Tim Murphy a Bill Murray. 4 de Novembro, 2008.

NETHERCUTT, Ron. The Early years. In: Letters From Evans. v.1, n.2, Nov/Dez., 1989. p.4-5.

O'REILLY, Ted. Interview with Bill Evans. In: Letter From Evans. v.2, n.3, Jan./Fev., 1991. p.10-15.

PETRAHN, Sean. Audio recording review: Bill Evans's solo sessions. v.11. In: Letter From Evans. v.2, n.5, Maio/Jun, 1991. p.11-12.

PETTINGER. Peter. Bill Evans: how my heart sings. New Haven: Yale University Press, 1998.

REILLY, Jack. The Harmony of Bill Evans. Milwaukee, WI: Hal Leonard Corporation, 1993.

SHADWICK, Keith. Bill Evans. Downbeat Magazine. 8 de dezembro, 1960.

. Bill Evans: everything happens to me: a musical biography. San Francisco: Backbeat Books, 2002.

TEACHOUT, Terry. Does Bill Evans swing?. Commentary. RILM. January, 1998. p.46-49.

WETZEL, Pascal. Bill Evans Fake Book. 2a ed. Prefácio de Harold Danko. New York: Ludlow Publishing, 2003.

WILLIAMS, Martin. Homage to Bill Evans. In: Bill Evans: The Complete Riverside Recordings. Notas de encarte. Berkeley, CA: Riverside Records, 1984.

\section{Nota}

10 sinal / indica barras de compasso. Assim, dois acordes entre dois destes sinais indicam que os mesmos são tocados o $1^{\circ}$ e $3^{\circ}$ tempos do compasso.

0 pianista, compositor e arranjador J. William (Bill) Murray graduou-se com o Bacharelado em Música e o Mestrado em Música (Composição e Jazz) pela Towson University in Towson, Maryland, EUA. Além disso, obteve o MBA em Economia com honra pela Kellogg Graduate School of Management e o Bacherelado em Economia com honra especial pela University of Colorado. Como performer, atua na região de Baltimore como solista e arranjador para grupos de jazz. Gravou suas obras em dois CDs Billy's touch e Moving On Atualmente, é Presidente da Baltimore Chamber Jazz Society e membro diretor da Towson University Foundation, University System of Maryland Foundation e Center Stage Theater.

Fausto Borém é Professor Titular da UFMG, onde criou o Mestrado e a Revista Per Musi. Pesquisador do CNPq desde 1994, publicou dois livros, três capítulos de livro, dezenas de artigos sobre práticas de performance e suas interfaces (composição, análise, musicologia, etnomusicologia da música popular e educação musical) em periódicos nacionais e internacionais, dezenas de edições de partituras e recitais nos principais eventos nacionais e internacionais de contrabaixo. Recebeu diversos prêmios no Brasil e no exterior como solista, teórico, compositor e professor. 